\title{
Capitalist-Worker Conflict and Involuntary Unemployment
}

\author{
MARTIN J. OSBORNE \\ Columbia University
}

\begin{abstract}
We study a simple model of the determination of the level of employment in which a capitalist decides how many workers to hire, and then bargains over the wage with those whom he hires. If the capitalist hires all the available workers, his position is weak since, in the event of a strike, he is unable to hire strike-breakers; for this reason he chooses to leave some workers ("involuntarily") unemployed. An increase in unemployment benefits which raises the cost of hiring strike-breakers affects the bargaining power of both capitalist and workers; under some conditions it leads to a reduction in unemployment.
\end{abstract}

\section{INTRODUCTION}

Casual observation suggests that in every advanced capitalist economy a significant portion of the workforce is persistently unemployed, yet in the dominant formal model of such an economy ("Walrasian equilibrium theory") such a situation is never a point of rest of the system. Beginning with Clower (1965) and Leijonhufvud (1968) on the one hand, and with Drèze (1975) on the other, there has recently been a number of attempts to modify this theory in such a way that there can be unemployment in "equilibrium". All these attempts ("non-Walrasian models") retain from Walrasian equilibrium theory the view of a capitalist economy as a system of markets which passively mediates the conflicting desires of the individuals in the economy. In the Walrasian equilibrium analysis this mediation is successful, while in the non-Walrasian models it is not. However, in both cases the basic image is of an economy in which the individuals interact passively rather than antagonistically. Both approaches also begin with an exchange economy. In some cases the analysis can be extended to incorporate production, but it is never the case that the way production is organized is of any consequence: it makes no difference whether capital hires labour, or labour hires capital. To this extent these models do not incorporate a distinguishing feature of a capitalist economy. Here we study a very simple model in which the struggle over the distribution of output is the centre of attention, and in which the fact that capital hires labour, rather than vice versa, is essential. The model views a capitalist economy not as a system for allocating resources, but as a way of organizing production which involves a particular set of power relations between its members. Our premise is that such a viewpoint illuminates some aspects of the phenomenon of unemployment which are otherwise obscured.

In the model we construct, unemployment arises not because the system is incapable of performing the task of coordination, but because the capitalists, who can decide how many workers to hire, are in a better position to secure a large fraction of the output if some workers remain unemployed. This sort of reasoning is certainly not new-Marx's argument concerning the "reserve army of the unemployed" is perhaps similar--though apparently it has not previously been formalized. At the basis of our model is the bargaining process between a capitalist and the workers he chooses to employ. There are other models of unemployment which are based on such a bargaining process. 
However, in many cases the unemployment which is generated is part of the bargain which is struck, and hence is really "voluntary". Such an outcome appears to be inevitable in any case where the positions of workers and capitalists are symmetric. Here we introduce an asymmetry and generate unemployment which is "involuntary".

In many of the non-Walrasian models, the unemployment which is predicted can be interpreted in a number of ways. For example, one can think of some of the workforce selling none of its labour-time, while the remainder sells all it wants to; or each worker may sell some fraction of the amount he would like to. In our model, the unemployment can be only of the first type, which is, by and large, the one we observe. In this sense our model yields a sharper prediction than do the non-Walrasian ones.

In the next section we outline the model. In Sections 3 and 4 we formulate a basic, atemporal version of it. This clearly expresses the idea discussed above, though since it is atemporal it is difficult to give it a completely convincing interpretation. In Sections 5 and 6 we elaborate upon the temporal structure, and analyse short-term and long-term models which preserve the essential features of the basic model. Section 7 contains a general discussion.

\section{AN OUTLINE OF THE MODEL}

We divide the economy into industries, and assume that in each industry there is one capitalist and a fixed pool of workers who possess the skills required to be employed in that industry (they cannot be employed elsewhere). The assumption of one capitalist per industry is not essential to our argument, though the model would have to be more sophisticated to deal with the case in which there is a number of capitalists in each industry, and the force of our analysis would be weakened (the more so the larger the number of capitalists; see the discussion in Section 7). The assumption that labour is immobile between industries is quite strong; it rules out any "competition" between industries for labour. The effect of relaxing it would be similar to that of having more than one capitalist per industry. It allows us to analyse each industry in isolation; subsequently we restrict attention to a single industry. ${ }^{1}$

We assume that the wage rate in the industry is the outcome of bargaining between the capitalist and some of the available workers. If the capitalist bargains with all the workers available in the industry, then all the individuals involved are symmetric. Under these circumstances (ignoring "frictions") we should expect the outcome to be efficientfor if there is a feasible plan which can benefit all the individuals, there is no reason why they should not all agree to it. In the prototypical capitalist economy this symmetry does not prevail, since capitalists can decide how many workers to hire, and bargain over wages solely with those whom they do hire; this is the assumption which we make here. In some capitalist economies, labour unions bargain over wages not only at the level of an industry, representing those employed therein, but even at the level of the nation, including in their considerations the welfare of unemployed workers. Our model deals with an economy in which bargaining does not go so far as to include the unemployed.

How many workers will the capitalist hire? It seems reasonable to suppose that if he hires all those available, his bargaining position with them will be quite weak-for if they go on strike, he will not be able to find any replacements. On the other hand, if he employs only a few workers the output produced will be small, and regardless of the bargain which is struck, his payoff will not be large. This suggests that he will choose to hire some, but not all, of the available workers. 
It remains to specify how the bargaining proceeds. We assume for simplicity that the workers who are hired form a union. One may be able to argue that it is best for them to do so. In any case, it is an inconsequential assumption: we could equally well assume, without affecting the model in any essential way, that the workers bargain as individuals (see the comments in Section 7). Now, when individuals or groups bargain, some of the actions they can take are significant because they allow them to achieve certain payoffs independently of the actions of their opponents. However, those actions which adversely affect their opponents' payoffs are also an important determinant of the outcome. Thus, the fact that workers can go on strike, and reduce the payoff to their employer, confers upon them considerable power; capitalists derive power from the fact that they can lay off or fire workers. In the bargaining model we use, these "threats" are of central importance. We assume that the workers whom the capitalist decides to hire can threaten to go on strike, and if they do so the capitalist can replace them with workers from the pool of those who are unemployed.

We assume that if the strike threat is carried out, each worker receives some fixed payoff (e.g. unemployment benefits). The versions of the model which we study differ in the determination of the payoff to the capitalist in this case. In the basic atemporal model of Section 3, the unit cost to the capitalist of hiring strike-breakers is fixed. In order for the model to make sense, this cost has to be relatively high. This is a reasonable assumption if we put the model in a short-term context, where there are significant costs (in excess of wages) involved in a turnover of personnel. (A version "of the model in which the adjustment costs are made explicit is studied in Section 5.) It is also reasonable in this setting to assume that the wage of the strike-breakers is given-it may be determined, for example, by the minimum wage, or the size of unemployment benefits.

If the strike-breakers are to be a long-run alternative to the existing workforce, then it is not reasonable to assume that their wage is determined by forces outside the industry. Rather, after a lag we should expect the workers to form a union and negotiate their wage. In this context, the transitory costs associated with the turnover of personnel are also insignificant. Adopting these assumptions, as we do in Section 7 , involves a simultaneous solution of the basic model for all sizes of the workforce. The arbitrariness of the strike-breakers' wage is removed, while the qualitative features of the basic model are preserved-in particular, in equilibrium the capitalist chooses to leave some workers unemployed.

Throughout, we use a simple bargaining model, due to Nash (1953). It does not take into account all the intricacies of a bargaining process which occurs over time and involves a sequence of offers and counteroffers. It is, however, sufficient to make our point; the outcome it predicts is sensitive, in an intuitively appealing way, to the sort of threats available to the bargaining parties.

Given the strategies available to the union and the capitalist, and the associated payoffs (defined in either of the ways described above), we can find, for each level of employment, the wage bargain which will be struck. Then for each level of employment, the capitalist knows what his profits will be, and can choose a level which maximizes these profits. It turns out that in a wide range of situations he chooses to employ fewer than the total number of workers available, so that there is some "involuntary unemployment".

An outcome where some workers are not employed is of course not Pareto efficientthere is a feasible allocation which is preferred by all individuals. However, it is not clear how such an allocation could be achieved, given the structure of the economy in our model. All the workers in the industry could form a union, and bargain with the 
capitalist, insisting that they all be employed. But the wage which is the outcome of bargaining in such a case might be lower than the wage reached under the assumptions of our model, so that not all of the workers would agree to such an arrangement. On a different level, we could argue that only when the workers are brought together at the workplace by the capitalist is it feasible for them to form a union.

\section{THE BASIC MODEL}

In the industry there is one capitalist, and a fixed pool of $n$ available workers. The employment opportunities of each worker are confined to this industry. Each worker is endowed with one unit of his own labour-time, and the capitalist is endowed with a fixed amount of capital which can produce output of a single good with the aid of workers according to the function $f: \mathbb{R}_{+} \rightarrow \mathbb{R}_{+}$(i.e. using the fixed amount of capital, $k$ workers can produce $f(k)$ units of output). The price of output is given and normalized to be 1 . The length of the working day is fixed, so that the capitalist can purchase labour-time only in discrete quantities: he simply decides how many workers to hire. In order to simplify, however, we assume that the "number of workers" can be any nonnegative real number. We also assume that

$$
f(0)=0, \quad \text { and } \quad f \text { is increasing, smooth, and strictly concave, }
$$

and that each individual has a utility function for money which is the identity. (The smoothness assumption on $f$ is convenient, though inessential.)

The employment level and wage in the industry are determined as follows. The capitalist decides how many workers (out of the $n$ available) to hire; those hired form a union; and the wage is derived from the solution of a Nash variable-threat bargaining game $^{2}$ between the capitalist and the union. If the capitalist decides to leave some workers unemployed, he does so because their presence provides a threat against those who are employed, so that the negotiated wage is relatively low.

To specify the bargaining games involving the capitalist and unions of various sizes, we need to delimit the strategies and payoffs. We shall in fact not make assumptions which pin down the strategy sets and payoff functions completely. It is enough to specify the existence of some "extreme" strategies, together with the associated payoffs (in the sense that any game in which these strategies are available has the same solution). Thus, we assume that the capitalist can "lock out" the workers, and that the union can "go on strike". In either case, the payoff to each worker is $w_{0}$, and the cost to the capitalist of using replacement workers from the pool of the $n-k$ who are unemployed is $r$. Both $w_{0}$ and $r$ are fixed in the basic model, and we assume that $w_{0}<\min (r, f(n) / n)$. (The latter ensures that the capitalist can profitably negotiate with some group of workers.)

Before stating the restrictions we impose on the strategy sets and payoff functions, we define precisely the optimal actions of the capitalist in the event of a strike by the $k$ workers with whom he is negotiating. The capitalist decides how many strike-breakers to hire by solving

$$
\max _{q}(f(q)-r q) \quad \text { subject to } 0 \leqq q \leqq n-k .
$$

Let $g(x)$ be the point where the slope of $f$ is $x$ (so that $g(x)=f^{\prime-1}(x)$ where this is defined, 
with suitable extensions otherwise). Then the maximum in (2) is

$$
\bar{\pi}(k ; r)= \begin{cases}f(g(r))-r g(r) & \text { if } 0 \leqq k \leqq n-g(r) \\ f(n-k)-r(n-k) & \text { if } n-g(r) \leqq k \leqq n .\end{cases}
$$

Given the concavity of $f, \pi$ is concave in $k$ for each fixed $r$; it is illustrated as a function of $k$ in Figure 1 .

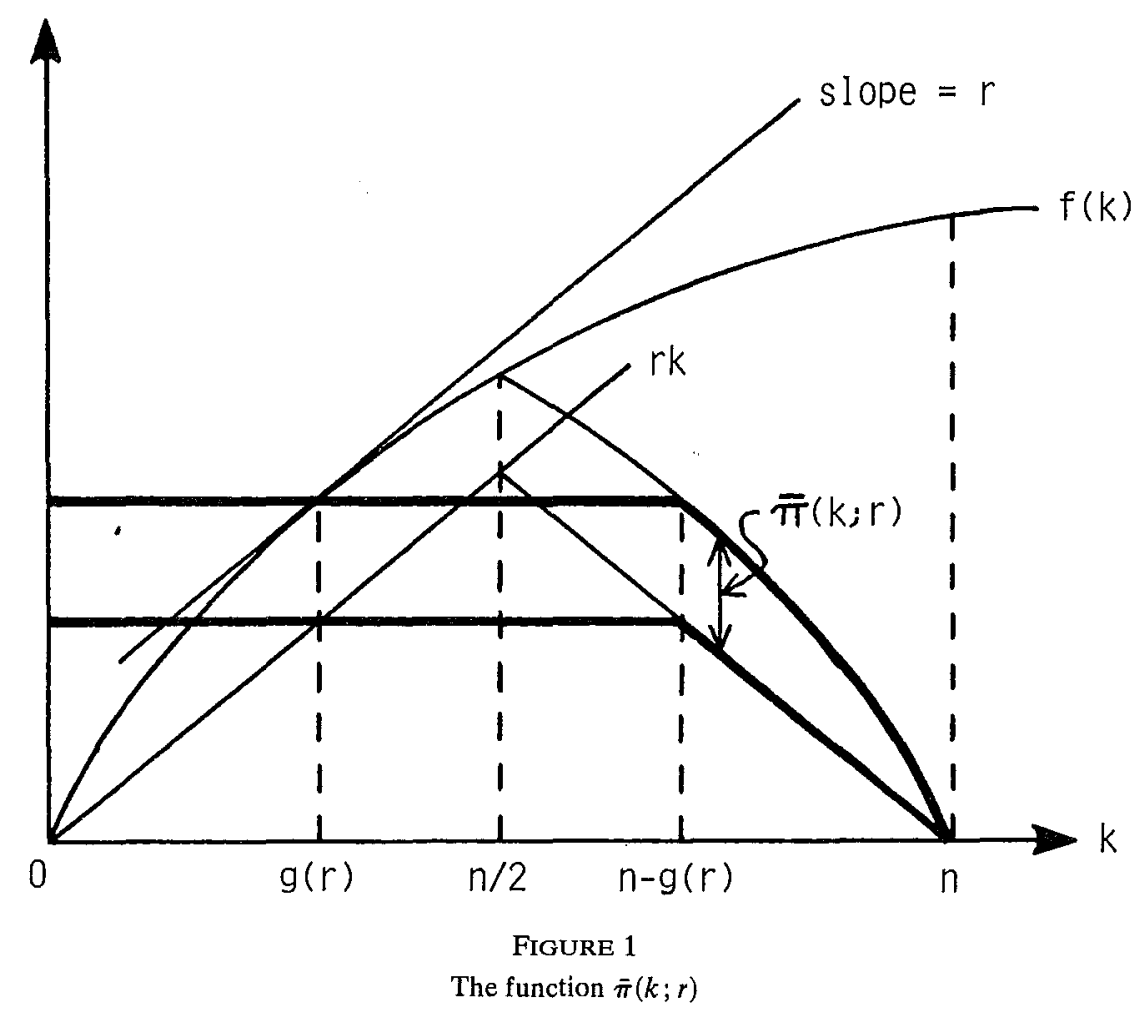

Now, if $k$ is small it may be that the sum of the payoffs to the capitalist and a $k$-member union when they carry out their threats $\left(\bar{\pi}(k ; r)+w_{0} k\right)$ exceeds the payoff which can be achieved by cooperation $(f(k))$. Let $\bar{k}\left(r, w_{0}\right)$ be the value of $k$ below which this is so. (Note that $\bar{k}\left(r, w_{0}\right)>g(r)$ since $r>w_{0}$.) For $k<\bar{k}\left(r, w_{0}\right)$ the parties will presumably not enter negotiations, and it makes no sense to define a bargaining game between them. If $k \geqq \bar{k}\left(r, w_{0}\right)$, then we can define a bargaining game; any reasonable set of rules will give a payoff of at least $w_{0} k$ to the union and $\bar{\pi}(k ; r)$ to the capitalist, since each party can guarantee these payoffs. However, by not entering into negotiations with anyone, but simply hiring workers at the cost $r$, the capitalist can always guarantee $\bar{\pi}(0 ; r)$. In order for the final outcome to be one in which negotiation actually takes place, we have to impose a condition on $r$ and $w_{0}$ so that the maximal negotiated profit of the capitalist (the negotiated profit for the employment level he chooses) exceeds $\bar{\pi}(0 ; r)$. In Lemma 1 we give such a condition; henceforth we assume that it is satisfied, so that the capitalist chooses some $k \geqq \bar{k}\left(r, w_{0}\right)$, and benefits from negotiation.

For each value of $k \geqq \bar{k}\left(r, w_{0}\right)$, we now define a bargaining game. Let the strategy set of the capitalist be $X^{c}$, and that of a $k$-member union be $X^{k}$; let the payoff functions 
be $h^{c}: X^{c} \times X^{k} \rightarrow \mathbb{R}_{+}$and $h^{k}: X^{c} \times X^{k} \rightarrow \mathbb{R}_{+}$respectively, and let $h(\sigma, \tau)=$ $\left(h^{c}(\sigma, t), h^{k}(\sigma, \tau)\right)$ for each $(\sigma, \tau) \in X^{c} \times X^{k}$. Finally, for each $k \in[0, n]$ let $C(k)=$ $\left\{x \in \mathbb{R}_{+}^{2}: x_{1}+x_{2} \leqq f(k)\right\}$. We assume the following. For each $k \in[0, n]$,

$$
h\left(X^{c}, X^{k}\right)=C(k)
$$

there exists $\tau_{0} \in X^{k}$ such that for all $\sigma \in X^{c}$,

$$
h^{c}\left(\sigma, \tau_{0}\right) \leqq \bar{\pi}(k ; r) \text { and } h^{k}\left(\sigma, \tau_{0}\right) \geqq w_{0} k
$$

and there exists $\sigma_{0} \in X^{c}$ such that for all $\tau \in X^{k}$,

$$
h^{c}\left(\sigma_{0}, \tau\right) \geqq \bar{\pi}(k ; r) \text { and } h^{k}\left(\sigma_{0}, \tau\right) \leqq w_{0} k .
$$

Assumption (4) says that the payoffs which are possible outcomes of agreement are precisely those which sum to at most $f(k)$, the total available output. The strategy $\tau_{0}$ of the union in (5) can be interpreted as that of going on strike; in this event the payoff to the capitalist is at most the maximized profit $\bar{\pi}(k ; r)$ defined in (3). Finally, the strategy $\sigma_{0}$ of the capitalist in (6) can be interpreted as that of "locking out" the union members, and hiring workers from the pool of the unemployed.

Only if $k \geqq \bar{k}\left(r, w_{0}\right)$ is there a game satisfying these assumptions (otherwise (4) and (6) are incompatible). For any such game, the following result gives the Nash variablethreat bargaining solution.

Proposition 1. The pair of strategies $\left(\sigma_{0}, \tau_{0}\right) \in X^{c} \times X^{k}$ (where $\sigma_{0}$ is defined in (6), and $\tau_{0}$ in (5)) is a pair of optimal threats in a strategic game satisfying (4), (5) and (6). The Nash solution of such a game is given by

$$
\left(\left(f(k)+\bar{\pi}(k ; r)-w_{0} k\right) / 2,\left(f(k)-\bar{\pi}(k ; r)+w_{0} k\right) / 2\right) .
$$

Before giving a proof, we note that one can associate the payoff to the union given in (7) with the wage rate $\left(f(k)-\tilde{\pi}(k ; r)+w_{0} k\right) / 2 k$. The value of this, for the value of $k$ which maximizes the payoff of the capitalist, is the wage rate which is paid to the workers who are hired.

Proof of Proposition 1. If $d \in C(k)$, let $s(d) \in C(k)$ be the Nash solution of the Bargaining Problem with agreement set $C(k)$ and (fixed) disagreement point $d$, i.e. let

$$
s(d)=\left(\left(f(k)+d_{1}-d_{2}\right) / 2,\left(f(k)-d_{1}+d_{2}\right) / 2\right) .
$$

To find the disagreement point which will be chosen, we have to find a pair of optimal threats, i.e. we have to find a pair $\left(\sigma^{*}, \tau^{*}\right) \in X^{c} \times X^{k}$ such that $s_{1}\left(h\left(\sigma^{*}, \tau^{*}\right)\right) \geqq$ $s_{1}\left(h\left(\sigma, \tau^{*}\right)\right)$ for all $\sigma \in X^{c}$, and $s_{2}\left(h\left(\sigma^{*}, \tau^{*}\right)\right) \geqq s_{2}\left(h\left(\sigma^{*}, \tau\right)\right)$ for all $\tau \in X^{k}$. Set $\left(\sigma^{*}, \tau^{*}\right)=$ $\left(\sigma_{0}, \tau_{0}\right)$, where $\sigma_{0}$ is given in (6) and $\tau_{0}$ is given in (5). Note that from (5) and (6) we have $h\left(\sigma_{0}, \tau_{0}\right)=\left(\bar{\pi}(k ; r), w_{0} k\right)$. Hence

using (5). So

$$
\begin{aligned}
s_{1}\left(h\left(\sigma_{0}, \tau_{0}\right)\right) & \left.=\left(f(k)+h^{c}\left(\sigma_{0}, \tau_{0}\right)-h^{k}\left(\sigma_{0}, \tau_{0}\right)\right) / 2 \quad \text { (using }(8)\right) \\
& =\left(f(k)+\bar{\pi}(k ; r)-w_{0} k\right) / 2 \\
& \geqq\left(f(k)+h^{\mathrm{c}}\left(\sigma, \tau_{0}\right)-h^{k}\left(\sigma, \tau_{0}\right)\right) / 2 \quad \text { for all } \sigma \in X^{c},
\end{aligned}
$$

$$
s_{1}\left(h\left(\sigma_{0}, \tau_{0}\right)\right) \geqq s_{1}\left(h\left(\sigma, \tau_{0}\right)\right) \quad \text { for all } \sigma \in X^{c} .
$$

A similar argument, using (6), establishes that $s_{2}\left(h\left(\sigma_{0}, \tau_{0}\right)\right) \geqq s_{2}\left(h\left(\sigma_{0}, \tau\right)\right)$ for all $\tau \in X^{k}$, 
so that $\left(\sigma_{0}, \tau_{0}\right)$ is a pair of optimal threats, and the Nash solution of the bargaining game is $s\left(h\left(\sigma_{0}, \tau_{0}\right)\right)=\left(\left(f(k)+\bar{\pi}(k ; r)-w_{0} k\right) / 2,\left(f(k)-\bar{\pi}(k ; r)+w_{0} k\right) / 2\right)$, completing the proof.

This result gives the outcome of bargaining for each size $k \geqq \bar{k}\left(r ; w_{0}\right)$ of the workforce. Let $\pi\left(k ; r, w_{0}\right)$ be the negotiated profit of a capitalist who bargains with a workforce of size $k$. Then from (7) and (3) we have

$$
\pi\left(k ; r, w_{0}\right)= \begin{cases}\left(f(k)+f(g(r))-r g(r)-w_{0} k\right) / 2 & \text { if } \bar{k}\left(r, w_{0}\right) \leqq k \leqq n-g(r) \\ \left(f(k)+f(n-k)-r(n-k)-w_{0} k\right) / 2 & \text { if } n-g(r) \leqq k \leqq n\end{cases}
$$

The capitalist chooses $k$ to maximize $\pi\left(k ; r, w_{0}\right)$. That is, given the cost $r$ of hiring strike-breakers and the value of $w_{0}$, he chooses a workforce of size $K\left(r, w_{0}\right)$, where

$$
K\left(r, w_{0}\right) \text { solves } \max _{k}\left\{\pi\left(k ; r, w_{0}\right): \vec{k}\left(r, w_{0}\right) \leqq k \leqq n\right\}
$$

The strict concavity of $f$ ensures that $\pi$ is strictly concave, so that $K\left(r, w_{0}\right)$ is unique. The determination of $K\left(r, w_{0}\right)$ is illustrated in Figure 2: if we add $\bar{\pi}(k ; r)$ (see Figure 1) to $f(k)$ and subtract $w_{0} k$ we obtain $2 \pi\left(k ; r, w_{0}\right)$, which of course attains its maximum at the same point as $\pi\left(k ; r, w_{0}\right)$ does.

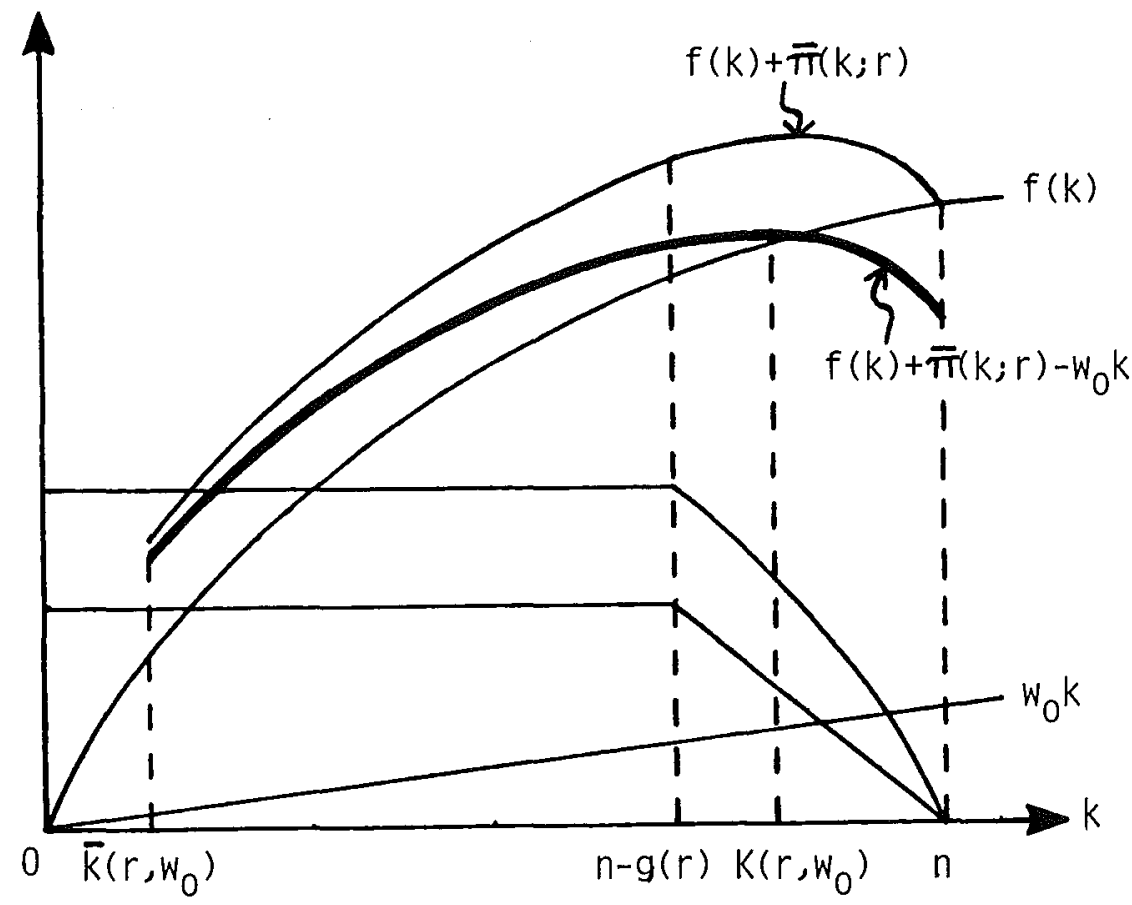

FIGURE 2

The determination of $K\left(r, w_{0}\right)$

We are interested in the properties of the function $K$, and in particular the circumstances under which $K\left(r, w_{0}\right)$ is less than $n$, i.e. the circumstances under which the capitalist chooses to employ fewer than the $n$ available workers, so that some remain unemployed. From the diagrams it appears that this will be so, given $w_{0}$, as long as $r$ is 
small enough (though it may still be large compared with the competitive wage $f^{\prime}(n)$ ). In the next section we investigate this question in detail, and study other aspects of the solution.

\section{THE CHARACTERISTICS OF THE SOLUTION OF THE BASIC MODEL}

We begin by giving the condition mentioned above which guarantees that the capitalist will choose to negotiate with some group of $k \geqq \bar{k}\left(r, w_{0}\right)$ workers, rather than simply hiring workers at the cost $r$. For each value of $r$, let $H(r)=\bar{\pi}(0 ; r)$.

Lemma 1. If $r \geqq \min \left\{f^{\prime}(n / 2), H^{-1}\left(\left(f(n)-w_{0} n\right) / 2\right)\right\}$, then $\pi\left(K\left(r, w_{0}\right) ; r, w_{0}\right) \geqq$
$\bar{\pi}(0 ; r)$.

Proof. If $r \geqq H^{-1}\left(\left(f(n)-w_{0} n\right) / 2\right)$ then $H(r) \leqq\left(f(n)-w_{0} n\right) / 2$. But $\pi\left(n ; r, w_{0}\right)=$ $\left(f(n)-w_{0} n\right) / 2$ for all values of $r($ see $(9))$, so that $\pi\left(K\left(r, w_{0}\right) ; r, w_{0}\right) \geqq\left(f(n)-w_{0} n\right) / 2$.

If $r \geqq f^{\prime}(n / 2)$ then $g(r) \leqq n / 2$, so $H(r)=f(g(r))-r g(r)<f(g(r))-w_{0} g(r)$, and so $\pi\left(K\left(r, w_{0}\right) ; r, w_{0}\right) \geqq \pi\left(g(r) ; r, w_{0}\right)=\left(f(g(r))+f(g(r))-r g(r)-w_{0} g(r)\right) / 2>H(r)$. This completes the proof.

Denote the bound given in this result by $\bar{r}\left(f, w_{0}\right)$. In the sequel (except in the long-run model, where $r$ does not enter) we assume that $f, r$, and $w_{0}$ satisfy ${ }^{3} r \geqq \bar{r}\left(f, w_{0}\right)$.

We can now answer a question which is central to our study: under what conditions does the basic model generate unemployment?

Proposition 2. $K\left(r, w_{0}\right)<n$ if and only if $f^{\prime}(n)-w_{0}<\max \left(0, f^{\prime}(0)-r\right)$.

Proof. First suppose that $f^{\prime}(0)>r$. Then $g(r)>0$, so that $n-g(r)<n$. From (9) we then have ${ }^{4}$

$$
\pi^{\prime}\left(n ; r, w_{0}\right)=\left(f^{\prime}(n)-f^{\prime}(0)+r-w_{0}\right) / 2
$$

so that if $f^{\prime}(n)-w_{0}<f^{\prime}(0)-r$ then $\pi^{\prime}\left(n ; r, w_{0}\right)<0$ and hence $K\left(r, w_{0}\right)<n . \quad\left(\pi\left(\cdot ; r, w_{0}\right)\right.$ has a negative slope at $k=n$, so that its maximum must occur when $k<n$.) On the other hand, if $K\left(r, w_{0}\right)<n$ then since $\pi\left(\cdot ; r, w_{0}\right)$ is strictly concave, we must have $\pi^{\prime}\left(n ; r, w_{0}\right)<$ 0 , or $f^{\prime}(n)-w_{0}<f^{\prime}(0)-r$.

Next suppose that $f^{\prime}(0)>r$. Then $g(r)=0$, so that from (9) we have $\pi^{\prime}\left(n ; r, w_{0}\right)=$ $\left(f^{\prime}(n)-w_{0}\right) / 2$, from which we can make an argument as in the previous case. This completes the proof. $\|$

If $f^{\prime}(0)>r$ then this result says that there is unemployment if and only if the difference between the cost of hiring strike-breakers and $w_{0}$ is sufficiently small. If $f^{\prime}(0)<r$, then $w_{0}$ simply has to be sufficiently large (larger than the competitive wage). If $r$ is small and there is some unemployment then in the event of a strike it is possible for the capitalist to hire strike-breakers and make a profit, while if there is no unemployment this is not possible. Thus if $r$ is small the capitalist is in a much better bargaining position when there is some unemployment than when there is none, and so chooses to hire fewer than the $n$ available workers. If $f^{\prime}(0)<r$ then no profit can be obtained in the event of a strike, so that the outcome of bargaining depends solely on the wage $w_{0}$. In fact, the negotiated payoff of a capitalist who bargains with $k$ workers is then precisely $(f(k)-$ $\left.w_{0} k\right) / 2$, so that some will be left unemployed whenever $w_{0}>f^{\prime}(n)$. 
Note that the "critical" values of $r$ and $w_{0}$ given in Proposition 2 depend on the degree of decreasing returns to scale which $f$ possesses: the higher that degree, the higher the values of $r-w_{0}$ which are still associated with unemployment. If $f^{\prime}(0)$ is infinite, then any values of $r$ and $w_{0}$ lead to some unemployment. Given this observation, it is clear that there is a wide range of functions $f$ for which there exist values of $r$ and $w_{0}$ satisfying the conditions in both Lemma 1 and Proposition 2.

We now study the function $K$ in more detail. First, we put bounds on $K\left(r, w_{0}\right)$, and hence on the size of the unemployment.

Proposition 3. For all values of $r$ and $w_{0}$ we have $\max \left\{n / 2, \min \left(n-g(r), g\left(w_{0}\right)\right)\right\} \leqq$ $K\left(r, w_{0}\right) \leqq \min \left\{n, g\left(w_{0}\right)\right\} ;$ as $r \rightarrow 0, K(r, 0) \rightarrow n / 2$.

Proof. Let the lower bound be $a\left(r, w_{0}\right)$ and the upper bound $b\left(w_{0}\right)$. Suppose that $n / 2<g(r)$. Then $a\left(r, w_{0}\right)=n / 2$, and, from (9), $\pi^{\prime}\left(n / 2 ; r, w_{0}\right)=\left(r-w_{0}\right) / 2>0$, so that given the concavity of $\pi$, its maximizer must exceed $n / 2$. By definition $\bar{K}\left(r, w_{0}\right) \leqq n$; if $b\left(w_{0}\right)=g\left(w_{0}\right)<n$ then $\pi^{\prime}\left(g\left(w_{0}\right) ; r, w_{0}\right)=\left(r-f^{\prime}(n-g(r))\right) / 2<0$ (since $n-g\left(w_{0}\right)<n-$ $g(r)<g(r))$, so that the maximizer of $\pi$ is at most $g\left(w_{0}\right)$. The other cases may be dealt with similarly. Finally, from (9) we have $\pi^{\prime}(n / 2 ; r, 0)=r / 2$, so as $r \rightarrow 0, K(r, 0) \rightarrow n / 2$ (if we were to allow $w_{0}=r=0$, then we should have $K(0,0)=n / 2$ ). This completes the proof. II

Using these bounds in (9), we have

$\pi\left(K\left(r, w_{0}\right) ; r, w_{0}\right)=\left\{\begin{array}{lr}\left(f\left(K\left(r, w_{0}\right)\right)+f(g(r))-r g(r)-w_{0} K\left(r, w_{0}\right)\right) / 2 & \text { if } g\left(w_{0}\right) \leqq n-g(r) \\ \left(f\left(K\left(r, w_{0}\right)\right)+f\left(n-K\left(r, w_{0}\right)\right)-r\left(n-K\left(r, w_{0}\right)\right)-w_{0} K\left(r, w_{0}\right)\right) / 2(11) & \text { if } n-g(r) \leqq g\left(w_{0}\right) .\end{array}\right.$

Since $k=K\left(r, w_{0}\right)$ maximizes $\pi\left(k ; r, w_{0}\right)$, this means that if $K\left(r, w_{0}\right)<n$, then

$$
0= \begin{cases}f^{\prime}\left(K\left(r, w_{0}\right)\right)-w_{0} & \text { if } g\left(w_{0}\right)<n-g(r) \\ f^{\prime}\left(K\left(r, w_{0}\right)\right)-f^{\prime}\left(n-K\left(r, w_{0}\right)\right)+r-w_{0} & \text { if } n-g(r)<g\left(w_{0}\right)\end{cases}
$$

If we differentiate these conditions with respect to $r$ and $w_{0}$, and use the concavity of $f$, we obtain the following.

Proposition 4. If $K\left(r, w_{0}\right)<n$ then $\partial K\left(r, w_{0}\right) / \partial w_{0}<0$. If in addition $g\left(w_{0}\right)<n-g(r)$ then $\partial K\left(r, w_{0}\right) / \partial r=0$, while if $n-g(r)<g\left(w_{0}\right)$ then $\partial K\left(r, w_{0}\right) / \partial r>0$.

If we fix $w_{0}$ and vary $r$ (with $r>w_{0}$ ), the last three results imply that $K$ has a form similar to one of those shown in Figures 3 and 4.

Now consider the effect of a change in the level of unemployment benefits. First assume that strikers receive these benefits, which are equal to $w_{0}$. From Proposition 4 we know that a change in $w_{0}$ alone leads to an increase in unemployment. However, $r$ may depend on the level of benefits. If we have $r=w_{0}+c_{0}$, for some fixed $c_{0}$ (for example, strike-breakers are paid a fixed premium over the unemployment benefits, and there is a fixed adjustment/training cost) then from (12) we find that if $n-g(r)<g\left(w_{0}\right)$ $\left(w_{0}\right.$ is relatively small), then a change in benefits has no effect on unemployment (while if $w_{0}$ is large, the effect is still negative). If $r=c_{0} w_{0}$, with $c_{0}>1$ (e.g. strike-breakers are paid a fixed markup over unemployment benefits) then if $w_{0}$ is small we find that an increase in benefits reduces unemployment. The reason for these results is the following. If an increase in benefits raises the cost of hiring strike-breakers, then it weakens the 


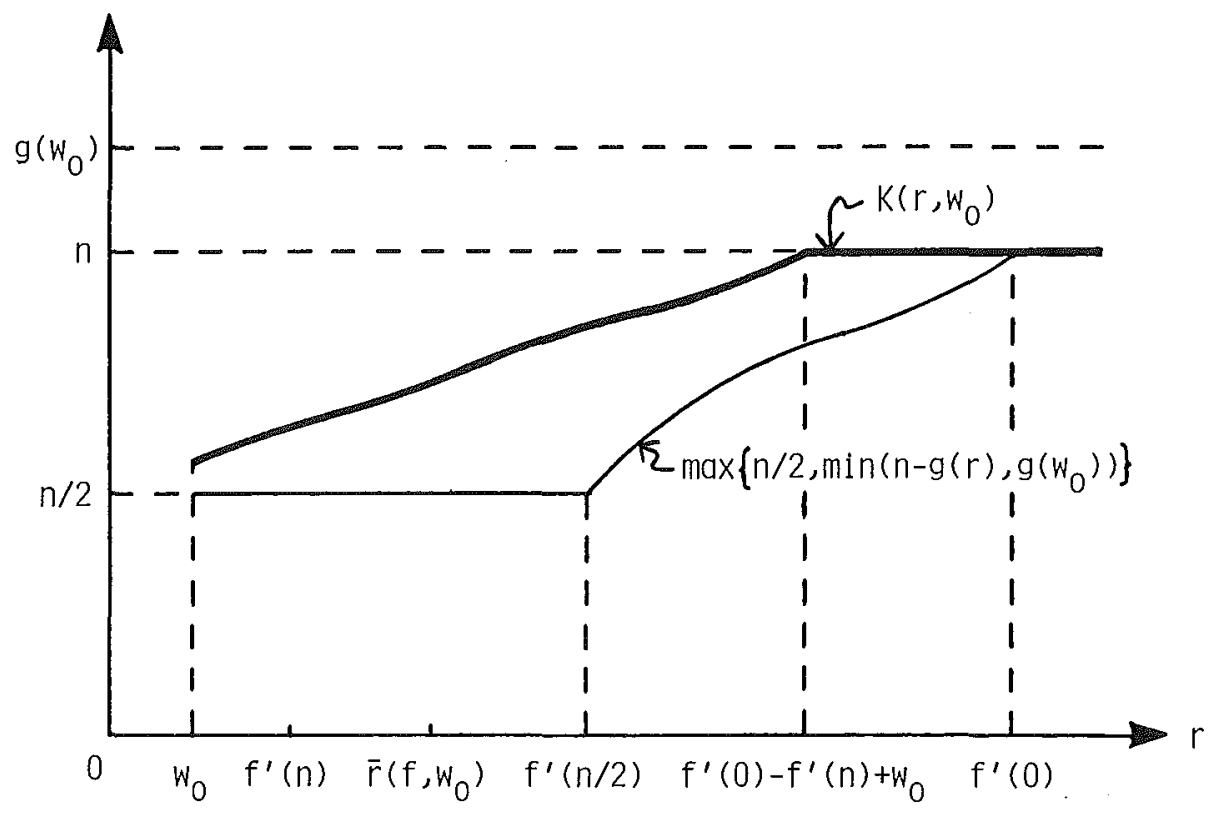

FIGURE 3

An example of $K\left(r, w_{0}\right)$ in the case $w_{0}<f^{\prime}(n)$

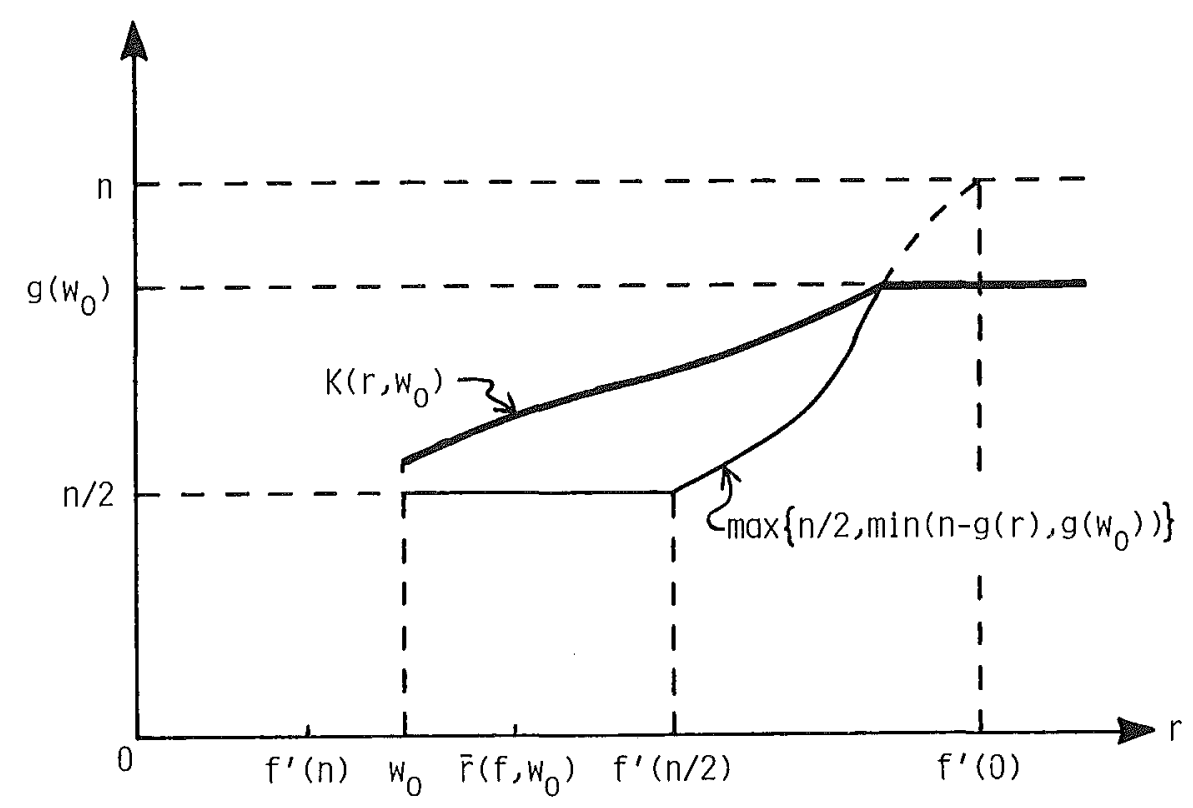

FIGURE 4

An example of $K\left(r, w_{0}\right)$ in the case $w_{0}>f^{\prime}(n)$ 
bargaining position of the capitalist when there is some unemployment (since he has to pay strike-breakers more in the event of a strike), and so reduces the advantage to the capitalist of there being unemployment. The increase in benefits also changes the bargaining position of the union, since its members are assured of a higher payoff in the event of a strike. Hence the net effect is uncertain, and depends on the precise relation between $r$ and $w_{0}$.

We can also analyse the case in which strikers do not receive any payoff $\left(w_{0}=0\right)$, but there is a constraint that the negotiated wage be at least $\bar{w}$. If $\bar{w}$ is a minimum wage, then the outcome of negotiation is constrained by law. If $\bar{w}$ is the level of unemployment benefits (which are, however, not paid to strikers) then the negotiated wage must exceed $\bar{w}$ in order for a group of workers to agree to negotiate. Assume that $r$ is an increasing function of $\bar{w}$. Then it follows from Proposition 4 that if $\bar{w}$ does not constrain the negotiated wage, an increase in $\bar{w}$, which leads to an increase in $r$, reduces the level of unemployment. Once $\bar{w}$ does act as a constraint on the negotiated wage, this may no longer be true. Thus under either set of assumptions, it is possible that an increase in unemployment benefits (or in the minimum wage) will reduce unemployment.

We close this section by briefly studying the behaviour of wages and profits as functions of $r$ and $w_{0}$. For each value of $\left(r, w_{0}\right)$, let $\Pi\left(r, w_{0}\right)$ and $W\left(r, w_{0}\right)$ be the negotiated profit and wage bills at the level of employment chosen by the capitalist-i.e.

$$
\Pi\left(r, w_{0}\right)=\pi\left(K\left(r, w_{0}\right) ; r, w_{0}\right) \quad \text { and } \quad W\left(r, w_{0}\right)=f\left(K\left(r, w_{0}\right)\right)-\pi\left(K\left(r, w_{0}\right) ; r, w_{0}\right) .
$$

Let $\Pi_{s}\left(r, w_{0}\right)=\Pi\left(r, w_{0}\right) / f\left(K\left(r, w_{0}\right)\right)$ and $W_{s}\left(r, w_{0}\right)=W\left(r, w_{0}\right) / f\left(K\left(r, w_{0}\right)\right)$ be the corresponding negotiated profit and wage shares. By differentiating in (11) and using (12) it is easy to show the following.

Proposition 5. For fixed $w_{0}, \Pi$ and $\Pi_{s}$ are nonincreasing in $r$, while $W$ and $W_{s}$ are nondecreasing in $r$. For fixed $r, \Pi$ is nonincreasing in $w_{0}$.

Since $K$ is nondecreasing in $r$, this means that if $w_{0}$ is fixed, a higher level of employment is associated with a higher negotiated wage bill and wage share, and a lower negotiated profit share. The behaviours of $\Pi_{s}, W$ and $W_{s}$ as functions of $w_{0}$ depend on the precise shape of the production function $f$. The same is true of the negotiated wage rate $w\left(r, w_{0}\right)=W\left(r, w_{0}\right) / K\left(r, w_{0}\right)$. We know that $w\left(r, w_{0}\right)>w_{0}$ for all pairs $\left(r, w_{0}\right)$, and it is possible to deduce some other properties of $w$ (e.g. if $\left(r, w_{0}\right)$ is such that $K\left(r, w_{0}\right)=n$ then $\left.w\left(r, w_{0}\right)=\left(f(n)+w_{0} n\right) / 2 n\right)$, but its variation with $\left(r, w_{0}\right)$ depends on the exact form of $f$.

\section{A SHORT-RUN VERSION OF THE MODEL}

The basic model described above is atemporal. In this and the next section we elaborate on the structure so that it may be given consistent short- and long-run interpretations. Our basic result on the generation of unemployment is unaffected in both cases, though the quantitative features of the model change (more so, in the long-run model of the next section).

Suppose that the firm has been in existence for several periods. In the current period economic conditions (the price level, the available technology) have somewhat changed relative to those of the last period. The previous wage contract has to be renegotiated, and the capitalist has the opportunity to change the size of the labour 
force. Such changes are not costless-they require some reorganization, and involve training any new workers who are hired. If the adjustment is not wholesale-for example, if the firm does not simultaneously fire a large fraction of the previous workforce and hire a large number of new workers-then we assume that the union remains intact as the negotiating body for the workers. However, if all the current workers are displaced by completely new ones, as is the case when strike-breakers are hired, we assume that there is a one-period lag before a new union is formed. In the meantime, the new workers are paid some fixed wage, which is related to the size of unemployment benefits. The unit labour cost to the firm in such a case is higher than this fixed wage, because of the cost of reorganization mentioned above. We are thus assuming that the time needed for adjustment is significant relative to the time period covered by a contract; we further assume that the cost of adjustment is high enough that it does not pay the capitalist to turn over the workforce every period (i.e. a condition analogous to that of Lemma 1 is satisfied). Since contracts are renegotiated every period, the firm bases its decisions on profits in the current period.

The major difference between the model here and the one defined previously thus involves the costs associated with adjustments in the size of the workforce. Let $R_{t}$ be the number of workers retained in the workforce from period $t-1$, let $H_{t}$ be the number newly hired, and let $S_{t}$ be the number fired from the period $t-1$ workforce. Let $C\left(R_{t}, H_{t}, S_{t}\right)$ be the adjustment cost involved in the change. Letting $k_{t}$ be the total size of the workforce in period $t$, we have $C\left(k_{t}, 0,0\right)=0$ (no change is costless). We assume that $C\left(0, k_{i}, k_{t-1}\right)=(r-\bar{w}) k_{i}$, where $\bar{w}$ is the fixed wage which the new (unorganized) workers are paid, so that the total cost of hiring $k_{t}$ strike-breakers is $r k_{t}$, as previously.

We assume that the adjustment cost is subtracted from output before the division of profits is negotiated (it would make no qualitative difference to assume that the cost is subtracted from the capitalist's negotiated profit after bargaining). If employment is

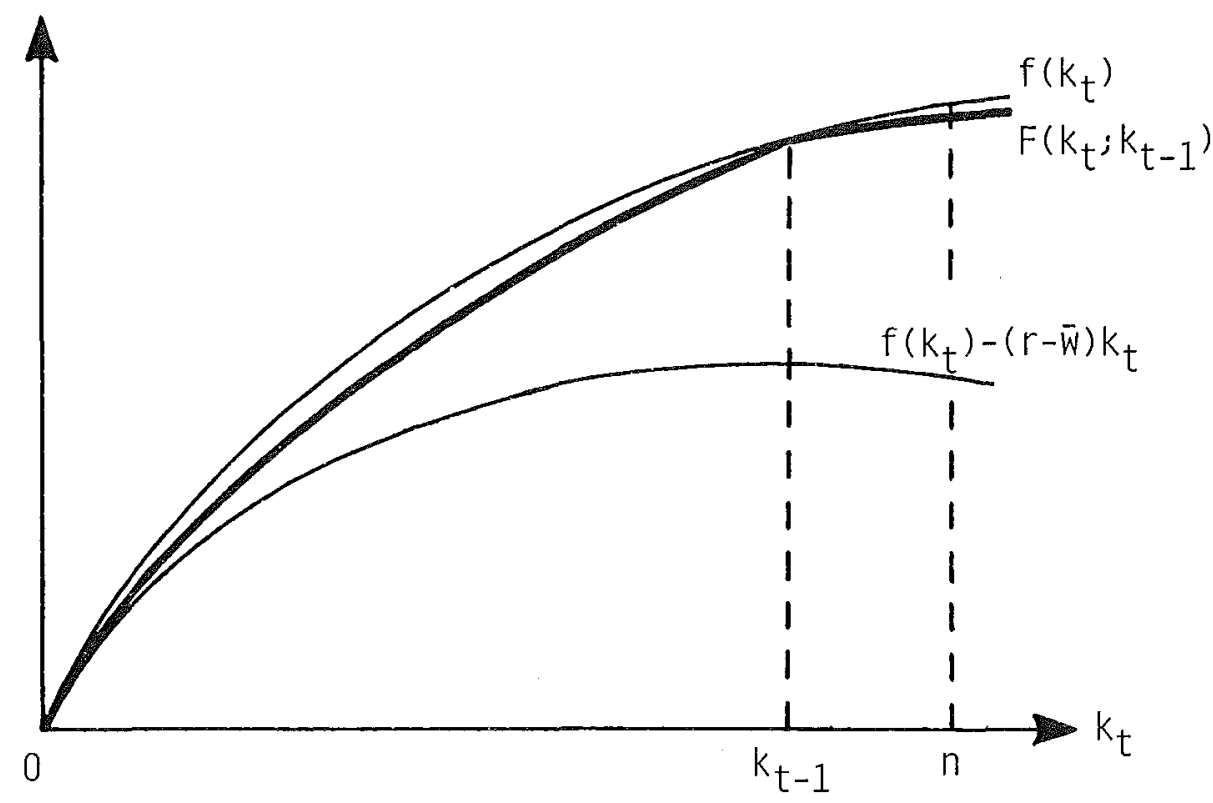

Figure 5

The function $F\left(k_{t} ; k_{t-1}\right)$ 
to be changed from $k_{t-1}$ to $k_{t}$, it can be done so least costlessly by retaining $R_{t}=$ $\min \left(k_{t-1}, k_{t}\right)$ and firing $S_{t}=\min \left(k_{t-1}-k_{t}, 0\right)$ workers from period $t-1$, and hiring $H_{t}=$ $\min \left(k_{t}-k_{t-1}, 0\right)$ new workers. The net output to be divided by negotiation is then $f\left(k_{t}\right)-C\left(R_{t}, H_{t}, S_{t}\right)=F\left(k_{t} ; k_{t-1}\right)$, say. An example is shown in Figure 5. We assume that $C\left(R_{t}, H_{t}, 0\right)$ and $C\left(R_{t}, 0, S_{t}\right)$ are increasing in $H_{t}$ and $S_{t}$ (the larger the reorganization, the more costly), and that $C$ is such that, for each value of $k_{t-1}, F\left(k_{t} ; k_{t-1}\right)$ is concave in $k_{t}$. We should expect $C\left(R_{t}, 0, S_{t}\right)$ to be relatively small-some reorganization, but no training is involved-and in any case we assume that $C\left(R_{t}, 0, S_{t}\right) \leqq(r-\bar{w}) R_{t}$ (the adjustment cost of retaining $R_{t}<k_{t-1}$ workers from last period does not exceed that from hiring (and training) $R_{t}$ new workers). If we assume that firing is costless, and the cost of reorganization is insignificant, then we have $C\left(R_{t}, 0, S_{t}\right)=0$ and $C\left(R_{t}, H_{t}, 0\right)=$ $(r-\bar{w}) H_{t}$, which in particular satisfies our assumptions. The value of $C\left(R_{t}, H_{t}, S_{t}\right)$ when both $H_{t}$ and $S_{t}$ are positive is irrelevant, since a strategy of simultaneously hiring new workers and firing some of the old ones is not one which maximizes the total output, nor is it an optimal threat (since the union members could respond by striking, and forcing $R_{t}$ to zero).

Since $C$ is specified so that the total cost of replacing the whole workforce in the event of a strike is the same as previously, the payoffs to the "extreme" threats specified in (5) and (6) remain the same, and hence these threats remain optimal. The negotiated payoffs, however, change (except in the case $k_{t}=k_{t-1}$ ) because of the costly nature of changes in workforce size. If $k_{t}$ workers are employed in period $t$, the negotiated payoffs to capitalist and union are

$$
\left(\left(F\left(k_{t} ; k_{t-1}\right)+\bar{\pi}\left(k_{t} ; r\right)-w_{0} k_{t}\right) / 2,\left(F\left(k_{t} ; k_{t-1}\right)-\bar{\pi}\left(k_{t} ; r\right)+w_{0} k_{t}\right) / 2\right) .
$$

( $\bar{\pi}$ is defined exactly as before, since the adjustment cost involved in hiring strike-breakers is taken into account in their unit cost $r$.) The previous analysis then applies by simply replacing, where appropriate, the production function $f$ by the conditional net production function $F\left(\cdot ; k_{t-1}\right)$.

The size of the unemployment at $t$ depends on $k_{t-1}$, but is still in general positive. For example, if $w_{0}=0$, then by Proposition 2 it is in fact positive if and only if ${ }^{5}$ $r<f^{\prime}(0)-F^{\prime}\left(n ; k_{t-1}\right)$. Our assumptions on $C$ imply that $F^{\prime}\left(n ; k_{t-1}\right)<f^{\prime}(n)$ if $k_{t-1}<n$, so that here there is unemployment for a wider range of values of $r$ than in the basic model.

If economic conditions stay constant for several periods then it is easy to see that the level of employment adjusts towards that of the basic model. If local changes in the labour force are costless, i.e. if for each value of $k_{t-1}$, the function $F\left(\cdot ; k_{t-1}\right)$ is differentiable at $k_{t-1}$, then the short-run employment levels converge to the level in the atemporal model. If local changes are not costless, employment may settle down at a level different from that produced in the atemporal model, but is still less than $n$ under the conditions above.

\section{A LONG-RUN VERSION OF THE MODEL}

Here we place the basic model of Sections 3 and 4 in a long-run setting. We assume that a long-term contract is being negotiated, so that adjustment costs are insignificant. In this context it is not appropriate to assume that the cost of hiring strike-breakers is determined by the size of some available alternative compensation. Rather, any strikebreakers who are hired will, after a lag, form a union of their own and negotiate their wage. Thus the alternative for the capitalist to continuing negotiations with his current workers is to negotiate with some other group of workers. Since the outcome of 
negotiations with $k$ workers depends on what would be the outcome if negotiations were to take place with subsets of the remaining $n-k$ workers, we need to solve the model simultaneously for all sizes of the workforce.

Let $W\left(k ; w_{0}\right)$ be the negotiated wage-bill when $k$ workers are hired (and strikers receive $w_{0}$ ). In negotiations with $k$ workers, the maximal alternative profit of the capitalist is then

$$
\bar{\pi}(k ; W)=\max _{q}\left\{f(q)-W\left(q ; w_{0}\right): 0 \leqq q \leqq n-k\right\} .
$$

Now, suppose that for some value of $k$ we have $\bar{\pi}(k ; W)+w_{0} k>f(k)$. Then the amount the bargaining parties can achieve independently exceeds that available when they cooperate, so that no mutually advantageous agreement is possible. It is natural to conclude, as we did in the previous versions of the model, that the capitalist will never choose to negotiate with a group of this size. However, it may be advantageous for the capitalist, when bargaining with another group of workers, to threaten to negotiate with a group of size $k$. This depends on the outcome of such negotiation. Thus, in the long-run setting, where all wages are negotiated, we need to define the outcome of negotiation for all sizes of the workforce. (Previously this was not necessary since the cost of hiring strike-breakers was determined outside the model.) We assume that the negotiated wage bill for each value of $k$ is the maximum of that given by Nash's model and the amount the workers can obtain independently, i.e. $\max \left\{\left(f(k)-\bar{\pi}(k ; W)+w_{0} k\right) / 2, w_{0} k\right\}$. Throughout we assume that $w_{0} \leqq \min \left\{f^{\prime}(n / 2), f(n) / n\right\}$; this guarantees, in particular, that there is some $k$ such that $f(k)>w_{0} k$.

Thus, a long-run negotiated wage-bill function $W^{*}$ satisfies

$$
W^{*}\left(k ; w_{0}\right)=\max \left\{\left(f(k)-\bar{\pi}\left(k ; W^{*}\right)+w_{0} k\right) / 2, w_{0} k\right\}
$$

for each $0 \leqq k \leqq n$. We show (Lemmas 2 and 3 , and Proposition 6) that there is a unique such function $W^{*}$, and that, given this function, the capitalist maximizes negotiated profit by choosing $k=n / 2$, with a negotiated wage of $w_{0}$. This result derives from the extreme competition between alternative groups of workers in the model. Any group of less than $n / 2$ workers can be replaced by another such group, and so the wage for them is driven down to $w_{0}$. For larger groups the negotiated wage may be higher; it turns out that it is high enough to make the profit-maximizing employment level $n / 2$.

We can modify the model by requiring that the negotiated wage always exceed some $\bar{w}>w_{0}$ ( $\bar{w}$ may be a minimum wage, or workers may require a wage greater than the unemployment benefit in order to be induced to work). If $\bar{w}<f^{\prime}(n / 2)$, this has the effect of making the negotiated wage equal to $\bar{w}$ even for some values of $k$ close to and larger than $n / 2$, so that the negotiated wage for the chosen workforce may also exceed $\bar{w}$. We shall not treat this case in detail. The formulation is straightforward, and the arguments similar to those when $\bar{w}=w_{0}$, which we now present.

First, we characterize $W^{*}$ in the following two results. Recall that we assume that $w_{0} \leqq \min \left\{f^{\prime}(n / 2), f(n) / n\right\}$.

Lemma 2. $W^{*}\left(k ; w_{0}\right)=w_{0} k$ for all $0 \leqq k \leqq n / 2$.

Proof. First consider the case $k=n / 2$. We have $\bar{\pi}\left(n / 2 ; W^{*}\right) \geqq$ $f(n / 2)-W^{*}\left(n / 2 ; w_{0}\right)$ (since $q=n / 2$ satisfies the constraint in (14)), so that

$$
W^{*}\left(n / 2 ; w_{0}\right) \leqq \max \left\{\left(W^{*}\left(n / 2 ; w_{0}\right)+w_{0} n / 2\right) / 2, w_{0} n / 2\right\} \text {. }
$$

Since $W^{*}\left(n / 2 ; w_{0}\right) \geqq w_{0} n / 2$ (see $\left.(15)\right)$, we have $W^{*}\left(n / 2 ; w_{0}\right)=w_{0} n / 2$. But then if 
$k \leqq n / 2$ we have $\bar{\pi}\left(k ; W^{*}\right) \geqq f(n / 2)-W^{*}\left(n / 2 ; w_{0}\right)=f(n / 2)-w_{0} n / 2$, so that

$$
\begin{aligned}
W^{*}\left(k ; w_{0}\right) & \leqq \max \left\{\left(f(k)-f(n / 2)+w_{0} n / 2+w_{0} k\right) / 2, w_{0} k\right\} \\
& =w_{0} k \quad\left(\text { since } w_{0} \leqq f^{\prime}(n / 2)\right) .
\end{aligned}
$$

Since $W^{*}\left(k ; w_{0}\right) \geqq w_{0} k$ we have $W^{*}\left(k ; w_{0}\right)=w_{0} k$, completing the proof. $\|$

Lemma 3. $W^{*}\left(k ; w_{0}\right)=\max \left\{\left(f(k)-f(n-k)+w_{0} n\right) / 2, w_{0} k\right\}$ for all $n / 2 \leqq k \leqq n$. If $n / 2 \leqq k \leqq g\left(w_{0}\right)$ then in fact $W^{*}\left(k ; w_{0}\right)=\left(f(k)-f(n-k)+w_{0} n\right) / 2$.

Proof. If $k \geqq n / 2$ then $\bar{\pi}\left(k ; W^{*}\right)=f(n-k)-w_{0}(n-k)$ (using Lemma 2 and the fact that $w_{0} \leqq f^{\prime}(n / 2)$ ), so that from (15) we have the first part of the result. But if $k=n / 2$ then $\left(f(k)-f(n-k)+w_{0} n\right) / 2=w_{0} n / 2$, and if $n / 2 \leqq k \leqq g\left(w_{0}\right)$, the derivative of $(f(k)-$ $\left.f(n-k)+w_{0} n\right) / 2$ is $\left(f^{\prime}(k)+f^{\prime}(n-k)\right) / 2 \geqq\left(w_{0}+w_{0}\right) / 2=w_{0}$, so that $(f(k)-f(n-k)+$ $\left.w_{0} n\right) / 2 \geqq w_{0} k$, completing the proof. $\|$

Given these results, the negotiated long-run profit $\pi\left(k ; W^{*}\right)$ of the capitalist when bargaining with $k$ workers is

$$
\begin{aligned}
\pi\left(k ; W^{*}\right) & =f(k)-W^{*}\left(k ; w_{0}\right) \\
& = \begin{cases}f(k)-w_{0} k & \text { if } 0 \leqq k \leqq n / 2 \\
\left(f(k)+f(n-k)-w_{0} n\right) / 2 & \text { if } n / 2 \leqq k \leqq g\left(w_{0}\right) \\
\min \left\{\left(f(k)+f(n-k)-w_{0} n\right) / 2, f(k)-w_{0} k\right\} & \text { if } g\left(w_{0}\right) \leqq k \leqq n .\end{cases}
\end{aligned}
$$

The capitalist chooses $k$ to maximize $\pi\left(k ; W^{*}\right)$. We show in the following that the maximizer is always precisely $n / 2$.

Proposition 6. For every value of $w_{0}$ (with $0 \leqq w_{0} \leqq \min \left(f^{\prime}(n / 2), f(n) / n\right)$ ), the long-run employment level is $n / 2$, with a negotiated wage of $w_{0}$.

Proof. From (16), $\pi\left(k ; W^{*}\right)$ is increasing up to $n / 2$, its right-hand derivative at $n / 2$ is zero, and if $n / 2<k<g\left(w_{0}\right)$, the second derivative is $\left(f^{\prime \prime}(k)+f^{\prime \prime}(n-k)\right) / 2<0$. Hence $\pi\left(n / 2 ; W^{*}\right) \geqq\left(f(k)+f(n-k)-w_{0} n\right) / 2$ for all $k \geqq n / 2$. Hence $k=n / 2$ maximizes $\pi\left(k ; W^{*}\right)$, and the associated wage is $W^{*}\left(n / 2 ; w_{0}\right) /(n / 2)=w_{0} . \|$

Thus our main result on the generation of unemployment survives in the long-run model; in this case the level of unemployment benefits (as reflected in $w_{0}$ ) has no effect on employment. Of course, in general we do not see long-run contracts negotiated, and if they were, we might expect the assumption that the labour pool is immobile to be strained. Nevertheless, if, at the point the contract is signed, there exist alternatives to the group of workers with whom negotiations are taking place, then the model is appropriate. Over time, unemployed workers may leave the pool, and join other pools, so that the unemployment becomes at least "hidden". But if they leave permanently, then when the contract is eventually renegotiated, more unemployment will be created; there is always a force "pushing" the economy in the direction of unemployment.

\section{DISCUSSION}

Our aim in this paper is not to present a complete theory of unemployment, but to study a very simple model which illustrates one aspect of the phenomenon. Here we shall 
attempt to assess the applicability of the model, and say something about the sensitivity of our results to changes in the assumptions.

Part of our model simply gives expression to the idea that if there is unemployment, labour is in a weak bargaining position. Claims to this effect are often made; presumably the idea behind them is something like the one we have used. Given this relationship between unemployment and bargaining power, we have concluded that, under certain assumptions, a profit-maximizing capitalist will choose to leave some workers unemployed, in order that wages be held down. The assumptions we use to draw this latter conclusion are quite strong. Our model exactly fits the situation in a "company town"; once there is some mobility between employers and occupations, the forces at work may be mitigated: However, in these latter situations, the analysis of the model does not completely collapse.

Consider, for example, how the basic model might be modified to cover situations where there are two capitalists facing a common pool of potential employees. If they collude, and all the workers form a single union, then we are back to the model which we have already analysed. Suppose they do not collude, and the employees of each capitalist form separate unions. Fix the cost of hiring strike-breakers, and regard the variables as functions of the size of the available labour force. (Previously we focused on the dependence on $r$, and suppressed the latter dependence.) If a single capitalist faces a situation in which $x$ workers are available to him, let $J(x)$ be the number of workers he wishes to hire ( $J$ is like the function $K$ we considered before; only the independent variable is different). Assume that if the employees of one of the capitalists go on strike, he can hire strike-breakers from the pool of the unemployed, but cannot "poach" the other capitalist's employees. (The wage a worker has to be paid in order to induce him to forsake his permanent job to become a temporary strike-breaker may be too high to make "poaching" worthwhile; certainly it does not seem to occur in practice.) Also, suppose that each capitalist assumes that there is no chance that both unions will go on strike simultaneously, and takes the other's actions as given. Then the sizes $k_{1}$ and $k_{2}$ which the capitalists choose for their labour forces are given by the solutions of

$$
k_{1}=J\left(n-k_{2}\right) \text { and } k_{2}=J\left(n-k_{1}\right) \text {. }
$$

(Given $k_{2}$, the first capitalist faces a situation where the available labour force is $n-k_{2}$, and similarly for the second capitalist.) We shall not examine these solutions in detail. We mercly claim that among them there is one for which $k_{1}=k_{2}$ (though there may be other, nonsymmetric solutions), and in this case the total size of the unemployment is lower than it would be if there were just one capitalist, but is still in general positive. The reason is that, given that strikes never occur simultaneously, the unemployed serve as potential strike-breakers for both capitalists. With more than two capitalists, the argument is similar, though the assumption that strikes never occur simultaneously is then less plausible. The more capitalists there are, the smaller the unemployment.

Thus, when there is more than one capitalist in an industry, our model needs to be elaborated. However, under some plausible assumptions our results are modified, but not qualitatively changed. Just as the competitive model is literally applicable only if the number of individuals is infinite, so our model literally requires a single capitalist and an immobile workforce. When these assumptions are relaxed, all is not immediately lost, especially if there is a small number of firms and a relatively captive pool of potential employees. To make a complete analysis of any actual situation one needs, of course, to consider many factors (like demand) which we have ignored; depending on the 
circumstances, the force which pushes in the direction of unemployment in our model will play a more, or less important role.

In the short-run version of the model, the cost of hiring strike-breakers is unexplained. Presumably, if there is the possibility of some labour mobility, it should be related to some wage available elsewhere in the economy. However, if we assume that it is actually equal to such a wage, at which work can always be obtained, then there is no room for the negotiated wage to be different. We need to assume that the "permanent" workforce has some advantage over potential strike-breakers, as we did in Section 5; preferably we should have a theory as to how this is determined.

Some of the assumptions we have made can clearly be relaxed without difficulty. For example, it is not essential that the capitalist produce just one good. Nor is it necessary that the employees of the capitalist form a union-we could assume that there is multilateral bargaining between the capitalist and all his employees. In this latter case, we should have to use a more elaborate bargaining model, but there is no reason to suspect that our results would qualitatively change.

First version received November 1980; final version accepted May 1983 (Eds.).

I am greatly indebted to Michael Carter, Paul Evans, Frank Hahn, Oliver Hart, Dan Hausman, Haruo Imai, Tracy Mott, Carolyn Pitchik, Robert Solow, and an anonymous referee, for comments and criticisms at various stages of this work. I also gratefully acknowledge the hospitality and financial assistance of the Institute for Advanced Studies at the Hebrew University of Jerusalem for the period January through June 1980, together with the financial assistance of the Council for Research in the Social Sciences at Columbia University in Summer 1982.

\section{NOTES}

1. We can construct a model of the whole economy in the following way. Given the prices of outputs, our analysis defines a level of employment for each industry. Given these employment levels, we can find total demand. The output prices can then be adjusted so that the output produced is compatible with this demand.

2. See Nash (1953) and Section I of Hart (1979) for discussions of the Nash variable-threat bargaining solution.

3. $\bar{r}\left(f, w_{0}\right)$ may be relatively small. For example, if $f(k)=A k^{\alpha}$ and $w_{0}=f^{\prime}(n) / 2$, then $\bar{r}\left(f, w_{0}\right) \leqq f^{\prime}(n)$ (the competitive wage) whenever $A \geqq 2(1-\alpha / 3)$. point $q$.

4. For each value of $\left(r, w_{0}\right), \pi^{\prime}\left(q ; r, w_{0}\right)$ is the derivative of the function $\pi\left(\cdot ; r, w_{0}\right)$ evaluated at the

5. In the proof of Proposition 2 it can be seen that the term $f^{\prime}(0)$ comes from $\bar{\pi}(k ; r)$, which is exactly the same as before.

\section{REFERENCES}

CLOWER, R. W. (1965), "The Keynesian Counter-Revolution: a Theoretical Appraisal", in F. H. Hahn and F. P. R. Brechling (eds.), The Theory of Interest Rates, 103-125. London: Macmillan.

DREZE, J. H. (1975), "Existence of an Exchange Equilibrium under Price Rigidities", International Economic Review, 16, 301-320.

HART, S. (1979), "Lecture Notes: Special Topics in Game Theory" (mimeo, Institute for Mathematical Studies in the Social Sciences (Economics), Stanford University).

NASH, J. F. (1953), "Two-Person Cooperative Games", Econometrica, 21, 128-140.

LEIJONHUVFUD, A. (1968), On Keynesian Economics and the Economics of Keynes (New York: Oxford University Press). 